\title{
Code 5: Service Improvement and Topic Development
}

The themes identified here were 'counselling pre-surgery on psychosexual concerns.' A theme of couples access as part of counselling was also identified (Table 64.1).

- 'Early initiation to Cialis and Vacuum pump devices, but also open access to GPs as part of GP education on early prescribing is needed.'-HCP 1.

- 'A standardised pathway is clearly required.'-HCP 1.

- 'Penile rehabilitation with physical rehabilitation, psychological rehabilitation and medical management should form part of this, however, a clear plan of implementation is required.'-HCP2.

- 'It is very necessary but thought to logistics and resources are required.'-HCP 3.

- 'Family are often worried about them being cured from cancer, and this is a lower priority.'-HCP4.

It was also felt that early initiation of therapy was the key.

In conclusion, by the healthcare professionals involved, there was felt with to be a significant lack in psychosexual care, with several contributory factors including resource issues. However, again it was felt, that a pathway would be a significant addition to support psychosexual care. The recommendations for this pathway based on the systematic review, patient focus group and healthcare professional interviews are as follows below.

Table 64.1 Code 5: Service improvement and topic development

\begin{tabular}{l|l}
\hline & Healthcare Professional Quote using Identity (HCP) numbers \\
\hline $\begin{array}{l}\text { Components of } \\
\text { pathway }\end{array}$ & $\begin{array}{l}\text { 'A joint clinic with a psychosexual counsellor and a specialist } \\
\text { nurse.'-HCP 5 }\end{array}$ \\
\hline $\begin{array}{l}\text { Components of } \\
\text { pathway }\end{array}$ & $\begin{array}{l}\text { Dedicated Specialist nurse, psychosexual counsellor, CCG } \\
\text { input.'-HCP6 }\end{array}$ \\
\hline $\begin{array}{l}\text { Requirement and } \\
\text { components of } \\
\text { pathway }\end{array}$ & $\begin{array}{l}\text { 'ED clinics are a way of delivering care really directly as part of a } \\
\text { routine service.' 'We need to address PDE5 inhibitors prescriptions at } \\
\text { hospital.'-HCP 7 }\end{array}$ \\
\hline
\end{tabular}

